Case Reports

\title{
Knowledge Creation and Virtual Knowledge ba: A Case Study of Car Dealer in Taiwan
}

\author{
Jui-Min Hsiao \\ Department of Applied Economic and Management, National ILan University Taiwan, Taiwan
}

Article history

Received: 17-03-2017

Revised: 20-09-2017

Accepted: 06-10-2017

Email:jmhsiao@niu.edu.tw

\begin{abstract}
The process of knowledge creation is continuous and has dynamic interactions amid tacit and explicit knowledge which generates a substantial context. This paper is aimed to establish a technology-based virtual knowledge $b a$, which enables the combination of an open flow of diverse knowledge and thus leads to the creation of more knowledge. A case study which focuses on a Ford car dealer is presented in order to identify how these IT tools work as a virtual interactive place on the website to affect the process of knowledge creation via the SECI modes and $b a$. The virtual knowledge $b a$ creates the opportunity for participants to work together in a creative place (e.g. in a community or an enterprise) for an organization which desires to promote knowledge creation on the website, in addition to proceed with the implementation of knowledge management systems to escalate the corporate knowledge management and improve the organization's competitiveness effectively.
\end{abstract}

Keywords: Knowledge Creation, SECI Modes, Virtual Knowledge $b a$, Information Technology

\section{Introduction}

Knowledge creation as a spiral process of interaction which is related to the integration of explicit and tacit knowledge so as to boost an organization's competitiveness in innovation (Nonaka et al., 2000). The knowledge creation outcomes are concrete and comprise boosted the satisfaction of employee and customer, an improved image and an escalated share valuation (Carlucci and Schiuma, 2007; Coulson-Thomas, 2004). In consideration of creating state-of-the-art knowledge, organizations employ interlinked processes that startup to share rich information and build the infrastructures of information technology which allow them to manage information acquired from both internal and external sources (Malhotra et al., 2005). Base on Kodama's literature (2005) investigated the dynamic interactions of the knowledge creation process at Fujitsu Ltd. In this Study, suggests that the development of new product in a high-tech industry needs to collect and integrate the various technologies to network strategic communities in all places of company in pursuance of sharing, transferring and therefore creating knowledge. Su et al. (2007) argued that managing the knowledge of product and customer in an organization with the Information Technology (IT) support transforms tacit knowledge into codified knowledge for value improving and risk reducing. Knowledge creation must thus link with technological abilities such as information and communication technologies which is conducive to conquer informational obstructions among technical, functional and cultural silos which restrict the internal creation and competitive advantages growth within organizations.

Creating knowledge requires a substantial context to be derived. $B a$ which literally means place in Japanese and was defined by Nonaka et al. (2000), suggests the context of $b a$ and its key concept is iteraction. Meanwhile, Information Technology (IT) inherently exists to corporate life worldwide and employees hinge on IT tools such as e-mail, telephone and videoconferencing for utilizing knowledge and interacting with others through the organization and with external networks (García-Muiña and Navas-López, 2007; Lin and Hsueh, 2006). However, despite heavy technology investment by organizations, a few enterprises have realized the potential of their IT supports to form a digital workplace that enables the interaction and open flow of diverse knowledge. This paper aims to establish a technology-Based Virtual Knowledge $b a(\mathrm{VKB})$, which enables the combination and open flow of diverse knowledge and thus brings into the knowledge-creating. First, THE SECI model is known as a knowledge creating and converting mechanism. It is comprised of the Socialization, Externalization, Combination and Internalization (SECI) modes and various 
$b a$ which are originally developed by Nonaka and Konno (1998) and introduced by Nonaka et al. (2000). Second, IT tools, including asynchronous and synchronous tools, are discussed. Finally, a case study which focuses on a Ford car dealer is presented in order to identify how these IT tools work as a virtual interactive place on the website to affect the process of knowledge creation via the SECI model and $b a$.

\section{Literature}

\section{Knowledge Types and Knowledge Creation}

The study of Nonaka and Takeuchi (1995) defined knowledge as justified worthy of acceptance and physically acquired skills. It can be classified into two types which are explicit and tacit. The dominant concept of Knowledge typologies was applied to differentiate tacit from explicit and we can see this from many literatures (Polanyi, 1966; Nonaka and Takeuchi, 1995; Senker, 1995). In the study, assumed that one of the pros of articulated knowledge to be shared easily is it is able to codify.

As reported by Nonaka and Takeuchi (1995), tacit knowledge is individual and context empirical, thus not easy to give description and communicate, whereas explicit knowledge can be elucidated as knowledge that is able to convey by informal or systematic language.

Tacit knowledge is subtle and harder to disseminated than those knowledge which can be codified among organizations (Kogut and Zander, 1993). According to Johnson's literature (1998) believed that explicit knowledge is captured in software and hardware way, as tacit knowledge is kept in different parts of brains.

Knowledge creation involves the interaction of knowledge adding and/or existing knowledge correcting (Shin et al., 2001). Nonaka and Konno (1998) mentioned that SECI model can be seen as a dynamic process in which exchanges and transformations of explicit and tacit knowledge are taking place continuously. A set of four core modes of knowledge creation have been determined in SECI model. The socialization mode (from tacit to tacit) is related to sharing tacit knowledge interpersonally. The externalization mode (from tacit to explicit) is usually driven by metaphors, hypotheses, analogies and models which expressed via articulated language. The combination mode (from explicit to explicit) is also known as converting explicit knowledge into sophisticated explicit knowledge sets. Finally, the mode of internalization (from explicit to tacit) is the conversion of explicit knowledge into tacit knowledge. The SECI process was shown in Fig. 1 (Nonaka et al., 2000).

In addition, Nonaka and Konno (1998) presented four corresponding types of $b a$ to the four stages of the SECI model (Fig. 2), namely, originating $b a$, interacting $b a$, cyber $b a$ and exercising $b a$. Each $b a$ involves a certain conversion process.

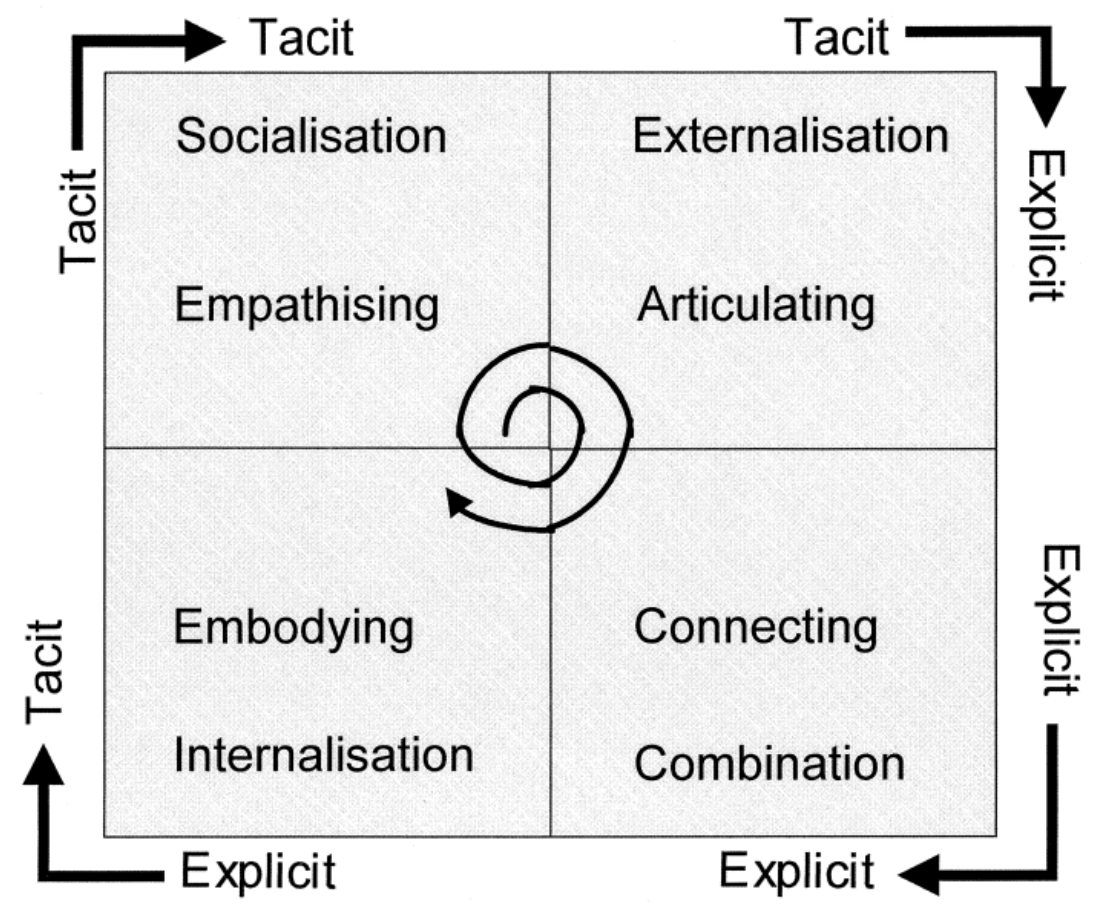

Fig. 1. The SECI process 


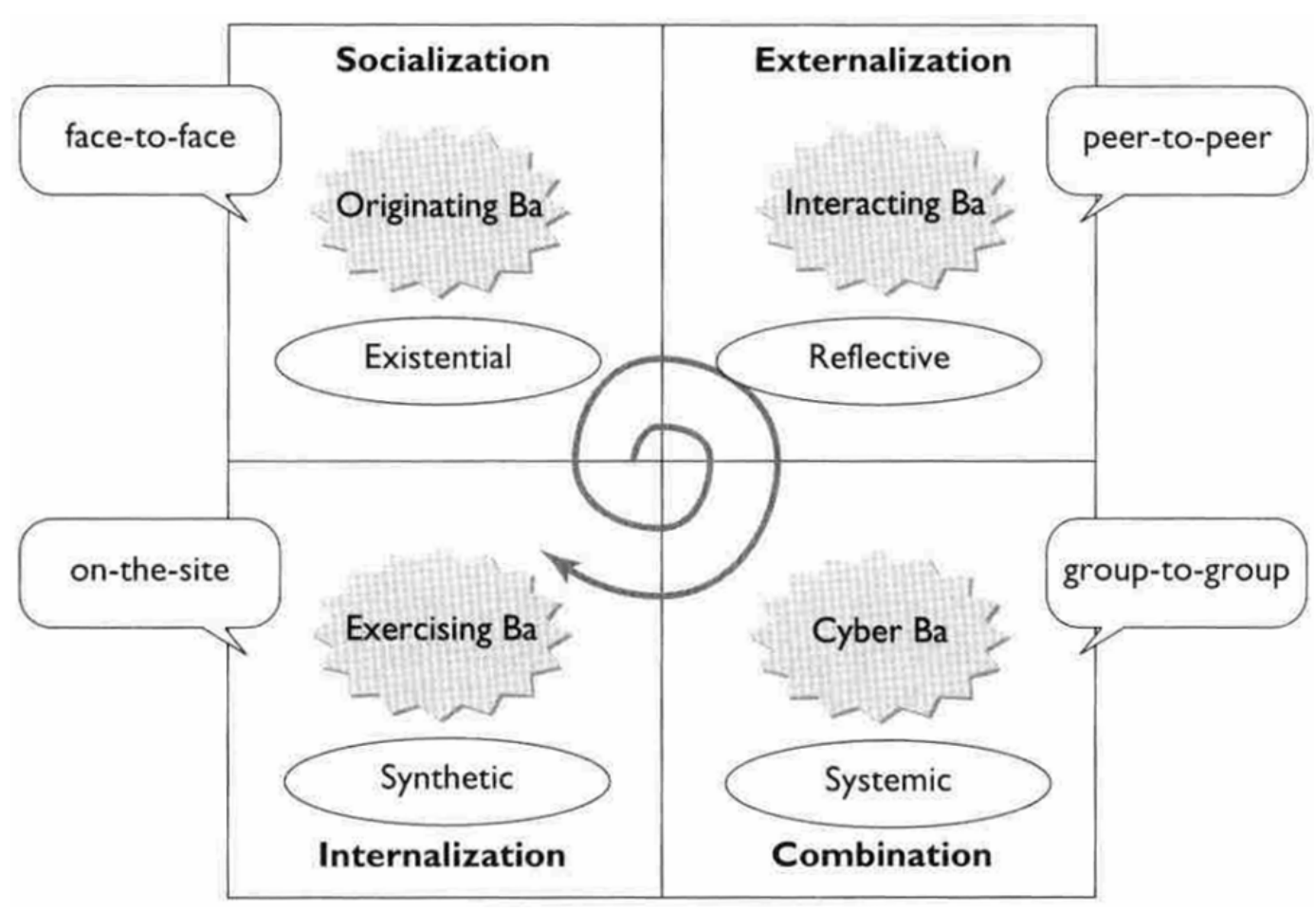

Fig. 2. Four types of $b a$

Nowadays, enterprises emphasize on improving their process of innovation (such as development of new products) through knowledge creation as well as routine activities. Aghdasi and Tehrani (2011) introduced the employment of SECI model to investigate the practices of organization. The results showed that the case company was started by utilizing certain implicit knowledge to the organizational practice, which is followed by the stage of Internalization or Socialization. There are some papers arguing that company performance can be positively influenced by knowledge creation. Ramírez and Morales (2011) used Nonaka's SECI model to examine how knowledge creation is linked to the importance of Reverse Logistics and their influence on the performance of organization. Their results showed that the importance of Reverse Logistics is affected by four modes of SECI model directly and indirectly, enhancing firm performance. Roy et al. (2012) considered via obtaining and managing knowledge-base resources can strengthen a firm's performance. Their findings indicated that effective knowledge management comprises the specific demands of balancing knowledge management strategy and varying knowledge-creating modes which are socialization, externalization, combination and internalization in view of organization types.

In addition, considering the conditions and environments is advantageous to facilitate knowledge creation. Nonaka et al. (2000) apply the Japanese word $b a$ to represent a common place or space serves as a knowledge creation foundation. $B a$ can be seen as a shared place for interpreting information into knowledge. It is the context shared by those participants in $b a$ through such interactions; the participants, the context itself, develop to advancing individuals further to create knowledge. $B a$ can be identified as four types, each of them corresponds to the four modes of knowledge creation. Originating $b a$ is a place where experience sharing of individuals primarily takes pace via face-toface interactions. It represents the socialization stage. Dialoguing $b a$ support the externalization step in knowledge creation. It is a space where tacit knowledge is made explicit and is shared through dialogue process and collaboration among individuals. Systemizing $b a$ consists of a combination of existing and new explicit knowledge, as explicit knowledge is relative to be formalized and easily transmitted to large segments of population. Finally, exercising $b a$ mainly offers a context for active and continuous individual learning and corresponds to the internalization step. Krahe et al. (2014) identified $b a$ space in doctoral studies of nursing and healthcare innovation. They believe $b a$ will bring educational innovation for nursing and healthcare educators. Thang et al. (2013) studied knowledge creation process in two Vietnamese green firms and found the impacts of a combination of leadership, teamwork and $b a$, corporate culture and human resource management. Also, Bartolacci et al. (2016) 
conducted a study on a web platform and found that the process of knowledge creation can occur within a virtual environment. The significant role of $b a$ is therefore identified.

\section{Technology-Based Virtual Knowledge ba}

Ueki and Ueki (2009) studied three Japanese firms and found that through the $b a$ using IT tools and organizational learning on promoting personnel training is crucial, to reveal individual experienced knowledge, tacit knowledge and know-how toward the realization, then to modify them as though organizational knowledge. It is essential to choose befitting technology for the virtual communication. The intranet and extranet are comprised of a wide range of technologies which can facilitate individual and collective knowledge. By using information technologies, computer network can learn and construct collective knowledge that enables virtual re-experience (Hemetsberger and Reinhardt, 2006; Kwon, 2006). It has been around for a while that an organization's knowledge creation is supported by many of the technologies and those tools can be characterized as asynchronous technologies and synchronous tools (Finger et al., 2006; Mohamed et al., 2004).

Asynchronous tools which are like e-mail, instant messaging, internet discussion forums and serve push, startup collaboration and communication over amount of time via a "different time-different place" way. Communication by means of asynchronous tools allows users to connect to the platform regardless of spatial and time barriers (Bosom et al., 2007). It is useful by applying these tools to continue dialogue and collaboration for a time and offer individuals with resources and information which can be accessed instantly, regardless of daytime or nighttime. In addition, asynchronous tools can be very applicable to retrieve the records of the a group's interactions, make collective knowledge possible to be shared easily and disseminated. According to Feller et al. (2006), a survey of 105 R\&D partnerships over the global telecommunications industry, the results show that, with a highly frequent usage of knowledge transfer mechanisms, such as e-mail among supply chain partners, explicit knowledge can be transferred asynchronously, which comes out with more desirable learning results and, in sequence, knowledge creation. Synchronous tools which are video-/audio conferencing, telephone, smart boards and chat rooms, enable real-time communication and collaboration in a "same timedifferent place" way. This can work in favor of finding the solution to specific and immediate problems between participants, be they students or tutors (Bosom et al., 2007). Wolfe (2007) evaluated the broadband videoconferencing's effectiveness among distributed research teams and confirmed that communication and dynamics of informal interaction can support knowledge creating and transferring.

\section{Research Methodology}

In contemplation of investigating knowledge creation progress in the automobile industry, a qualitative research approach was applied in this study. According to the literature of Yin (1994) mentioned that an approach of a case study was chosen, we can see it is appropriate when explorative questions are included and a contemporary phenomenon stays in focus. A case study includes methodically gathering sufficient information of a specific individual unit, situation, event or group to allow the researcher to effectively elaborate a thesis or principle. Moreover, the study of Hamel et al. (1993) mentioned that case study is not just seen as a data-collecting technique, but a methodological approach which comprises two or more of data-gathering methods to guarantee a broad perspective (Hamel et al., 1993). In Yin's point of view (1993), when "how" and "why" questions are posed, the events are slightly controlled by the investigator and contemporary phenomena is on focus, the case study can be preferred.

Several means of data collection can be adopted for case study research. Thus, several semi-structured and open-ended interviews were conducted in this study. We obtained data by in-depth interviews with salespersons and sales department managers. Meanwhile, the methods of audio-taping and transcribing verbatim were conducted for the contents of the interviews. And observations and informal conversations also made a contribution toward data-gathering process.

\section{Case Study of Ford-Right Co., Ltd}

\section{Company Profile}

Ford-Right Co., Ltd. was established on April 29 for the integration purpose of four dealers in Tainan and now the biggest Ford car dealer yet became. It mainly serves in Yulin, Ciayi and Tainan area and has been seen as the exclusive distributor of FORD Lio Ho Motor Company Ltd. Business items include automobile trading, repair and maintenance service, parts and accessories trading, examination service, automobile loan, automobile insurance and second-hand trading. Currently, there are 14 Ford-Right's dealer locators in service.

\section{Knowledge Creation in Ford-Right}

Data were analyzed with content analysis method. Nonaka's knowledge creation theory has been used as a qualitative approach to elucidate what the process of knowledge creation is in Ford-Right. According to Nonaka's theory, knowledge creation in Ford-Right was shown on Table 1 and details were described afterwards. 


\begin{tabular}{|c|c|c|c|c|c|}
\hline Core process & $\begin{array}{l}\text { Knowledge } \\
\text { before conversion }\end{array}$ & $\begin{array}{l}\text { Knowledge } \\
\text { conversion mode }\end{array}$ & $B a$ & Type of $B a$ & $\begin{array}{l}\text { Knowledge after } \\
\text { conversion }\end{array}$ \\
\hline $\begin{array}{l}\text { Customer communication } \\
\text { process }\end{array}$ & Customer focus & Socialization & $\begin{array}{l}\text { Video conferencing } \\
\text { and online chat function }\end{array}$ & $\begin{array}{l}\text { Virtual } \\
\text { originating } b a\end{array}$ & $\begin{array}{l}\text { Product } \\
\text { preferences }\end{array}$ \\
\hline $\begin{array}{l}\text { Customer perception } \\
\text { obtaining and } \\
\text { analysis process }\end{array}$ & $\begin{array}{l}\text { Difference between } \\
\text { customer expectations } \\
\text { and perception }\end{array}$ & Externalization & $\begin{array}{l}\text { Web discussion } \\
\text { forums and annotation } \\
\text { applications }\end{array}$ & $\begin{array}{l}\text { Virtual dialoguing } \\
b a\end{array}$ & $\begin{array}{l}\text { Product and process } \\
\text { conformity }\end{array}$ \\
\hline $\begin{array}{l}\text { Continual manufacturing } \\
\text { process improvement process }\end{array}$ & $\begin{array}{l}\text { Causes of } \\
\text { nonconformities }\end{array}$ & Combination & Issue Management system & $\begin{array}{l}\text { Virtual systemizing } \\
b a\end{array}$ & Corrective action \\
\hline $\begin{array}{l}\text { Supplier development } \\
\text { process }\end{array}$ & $\begin{array}{l}\text { Documented technical } \\
\text { or process know-how }\end{array}$ & Internalization & $\begin{array}{l}\text { Audio/video stream } \\
\text { presentations and } \\
\text { web conferencing }\end{array}$ & $\begin{array}{l}\text { Virtual exercising } \\
b a\end{array}$ & Suppliers' ability \\
\hline
\end{tabular}

\section{Customer Communication Process: A Socialization Mode}

Most automobile selling companies in Taiwan, like Ford-Right Co., Ltd., are constantly facing intense competition resulting from a withering market and uncertainties of orders. Ford-Right uses IT tools such as video/audio conferencing, instant messaging and email to support the communication process. Thus, the knowledge creation mode of the communication process with customers in Ford-Right can be identified as a socialization mode, where its crossfunctional company team members can learn the customer product preferences which is also what we call tacit knowledge. These IT tools provide a virtual place as a virtual originating $b a$ and members of the cross-functional company team socialize, using video conferencing and online chats, to share tacit knowledge (feelings, emotions, experiences and mental models) with colleagues and customers. There is high level interaction which is provided by the synchronous environment with several on-line participants, leads to a more collaborative and higher quality knowledge construction process, with the experience so effortless that it is like talking to the other participants face to face.

\section{The Process of Obtaining and Analyzing Customer Perceptions: An Externalization Mode}

Ford-Right creates a questionnaire to be applied for planned intervals, which includes a diversification of satisfaction questions attribute with a ten-point Likert scale and an end-anchored scale to collect data of customer's perceptions, which was examined and converted into actionable information. Thus, the knowledge creation mode, which obtains and analyzes customer perceptions, can be seen as an externalization mode. And tacit knowledge related to customer perceptions, just as the differences with the expectations of customer, which is seen explicit in the customer satisfaction reports related to product and process conformity, service of delivery and after-sale in pursuance of the goal of promoting customer satisfaction. Ford-Right uses web discussion forums and annotation applications to support the process of obtaining and analyzing customer perceptions with colleagues and suppliers. It supports to facilitate innovative and cardinal dialogue as concerns customer satisfaction among participants. The IT tools work as a dialoguing $b a$, which will provide a means of dealing with the acquisition, revision and transfer of knowledge concepts and conceptual issues related to the subject could be externalized through documents, texts, files, papers and bibliographical references (explicit knowledge).

\section{The Process of Continual Manufacturing Improvement: A Combination Mode}

One of the competitive strategies of Taiwanese firms is continuous process improvement, since it allows them to face irregular sales demands and inconsistent production plans. Firms in Taiwan strive for competitiveness by developing the knowledge and skills for continual process improvement, which are the collective learning of the organization and occupy a critical role for firm competitiveness. Ford-Right implements an information system, called Issue Management (IM), to examine and process data related to non-functioning products coming from each manufacturing procedure. The intention of the IM system is to gather the needs of the multiple internal customers in each procedure. Nevertheless, in FordRight, the importance of customer satisfaction was on external customers, the IM system can be employed equally effectively as investigating internal customer satisfaction. This will offer a stage for Ford-Right to assess improvements in internal processes which eventually bring on improved external customer satisfaction. Therefore, the IM system, systemizing $b a$, alters and processes synthetic knowledge about nonconformities of internal customer's dissatisfactions, their causes and corrective action, in written reports.

\section{Supplier Development Process: An Internalization Mode}

Enterprises in Taiwan are inclined to nominate a greater importance on the basis operations capability and 
extensively employ outsourcing to cultivate the flexibility and responsiveness of operation capabilities to handle emergencies. These exceptional systems are closely cooperative networks which connect assorted specialized and mutually supplemental organization. In consideration of maintaining a network of competent suppliers to enhance performance of purchase and to become more sensitive to customer preferences, Ford-Right implements supplier development training programs. These training programs can help the company's suppliers share experiential knowledge of improvement, such as via shared hands-on experience, the statistical skills and know-how can be established. Ford-Right uses IT tools such as audio/video stream presentations and web conferencing to support these training programs. These tools make communication among geographically distributed people simple, rapid and efficient and in this way separated sites become more like a by-itself face-to-face environment. Thus, the knowledge creation mode of the supplier development training programs can be identified as an internalization mode. These IT tools work as an exercising $b a$. In this $b a$, explicit knowledge can be seen as a component of the individual's knowledge base (e.g. mental model) also an asset for the supplier of Ford-Right.

\section{Discussion}

There are four types of technology-based virtual knowledge $b a$, involved in this following discussion, which show how the different virtual $b a$ can leverage the knowledge creation process in an organization. Table 2 shows these interaction tools.

\section{Virtual Originating ba}

To perform effectively in markets that are becoming increasingly turbulent and volatile, organizations should form collaborative relationships with their business partners. Along with a willingness to share knowledge, more communication for longterm cooperation is essential for Collaborative relationships (Grossman, 2004). Therefore, communication will be enhanced and bring on the rapid digestion of tacit knowledge due to the greater cultural understanding of relational partners. The socialization mode is connected to establish fields of interaction in which individuals share experiences and tacit knowledge. The virtual originating $b a$ mainly uses information technology to offer a virtual place for members of organization and its business partners share awareness, emotions, experiences and mental models. In a virtual originating $b a$, participants socialize, using the video conferencing and online chat function to share tacit knowledge (awareness, emotions, experiences and mental models) with colleagues. The on-line synchronous environment with several on-line participants, leads to a more collaborative and higher quality knowledge construction process, with the experience so effortless that it is like talking to the other participants face to face.

\section{Virtual Dialoguing ba}

When one attempts to conceptualize an image, its essence is basically expressed in language by he or she. Writing is a way of transforming tacit knowledge into articulated knowledge which is for illustrative purpose (Emig, 1983). Knowledge documentation examines, organizes and records knowledge. It can be seen as a key demonstration of knowledge and proffer an approach for its successful dissemination (Heng, 2001). A virtual dialoguing $b a$ will provide a means of dealing with the acquisition, revision and transfer of knowledge concepts. It is the virtual space where tacit knowledge is made explicit, then leads to accelerate the process of externalization conversion. In the dialoguing $b a$, participants use the web discussion forums to express, develop and share tacit knowledge and discuss issues in specific forums and thus the significance of information will be identified, as well as the participant's relationship to it.

\section{Virtual Systemizing ba}

Supporting management decisions is an information system's primary goal. It grants enterprises to integrate assorted department's information which are logistics, employment recruiting and management, cost accounting and other features related to production systems in consideration of facilitating the learning process, the learning infrastructure creation, innovation and improvement loops (Soliman and Youssef, 2001). The combination mode consists of many channels of communication, like face-to-face talking (socialization), communication networks (Internet, information system), use of writing (aspects of externalization) and written media (information analysis reports). That is a formal, systematic language derives from a transmittable knowledge. Thus, the configurations are a strategy of codification in which knowledge is codified and stored in databases where it is easy to access and utilize for organization's individuals (Turban et al., 2001). The virtual systemizing ba mainly focuses on combining explicit knowledge. The explicit knowledge combination is much efficiently supported in collaborative tools to make the knowledge database and information retrieval quicker, cheaper and more reliable, making the sharing of remote knowledge resources easy and fast. 
Table 2. Interaction tools

\begin{tabular}{|c|c|c|c|}
\hline Tool & Usage & Interactive attributes & Classification of VKB \\
\hline Discussion forum & $\begin{array}{l}\text { Dialogue that occurs over a period of time, } \\
\text { users can get or share ideas and knowledge } \\
\text { through the web discussion forum }\end{array}$ & & Virtual dialoguing $b a$ \\
\hline $\mathrm{B} \log \mathrm{s}$ & Sharing ideas and comments & Asynchronous & Virtual systemizing $b a$ \\
\hline Messaging (E-mail, SMS) & Sharing knowledge & & Virtual originating $b a$ \\
\hline $\begin{array}{l}\text { Streaming audio/ } \\
\text { video presentation }\end{array}$ & $\begin{array}{l}\text { Communicating or teaching, } \\
\text { self-directed training }\end{array}$ & & Virtual exercising $b a$ \\
\hline $\begin{array}{l}\text { Document categorization } \\
\text { and libraries }\end{array}$ & $\begin{array}{l}\text { Managing resources and } \\
\text { knowledge categorization }\end{array}$ & & Virtual systemizing $b a$ \\
\hline Databases storage & $\begin{array}{l}\text { Managing and combing information or } \\
\text { knowledge, knowledge storage and retrieval }\end{array}$ & & Virtual systemizing $b a$ \\
\hline Web conferencing & $\begin{array}{l}\text { Sharing presentations and knowledge, } \\
\text { getting more information and knowledge } \\
\text { from real-time conferences }\end{array}$ & & $\begin{array}{l}\text { Virtual exercising } b a \\
\text { Virtual originating } b a\end{array}$ \\
\hline Video/Audio conferencing & $\begin{array}{l}\text { In-depth discussions with higher-touch and } \\
\text { face-to-face interactions }\end{array}$ & & Virtual originating $b a$ \\
\hline Chat rooms & $\begin{array}{l}\text { Knowledge or information sharing about } \\
\text { low-complexity issues. }\end{array}$ & & Virtual originating $b a$ \\
\hline White boarding & $\begin{array}{l}\text { Co-development of ideas or knowledge, real-time } \\
\text { interactive training and sharing }\end{array}$ & & Virtual dialoguing $b a$ \\
\hline
\end{tabular}

\section{Virtual Exercising ba}

A firm builds up its organizational learning through a process of acquiring information, knowledge understanding, know-how, techniques and practices which come out with the changes in its system (Argyris and Schon, 1996). Via the learning process, each organizational member accomplished specialized knowledge which is relevant to his or her own assignment (Ryu et al., 2005). The virtual exercising $b a$ mainly focuses on the transformation of explicit knowledge to tacit knowledge. In the virtual exercising $b a$, the combining of theory and practice could be internalized and thus explicit knowledge becomes tacit knowledge. The participants get training from the organization's knowledge object repository, using virtual exercising $b a$ applications to learn new concepts or methods in the virtual framework. The knowledge objects can be defined and categorized and thus participants can easily select them for training.

\section{Conclusion}

In this investigation, a case study is administered to propose the application of virtual knowledge $b a$, which integrates various asynchronous and synchronous IT tools. The virtual knowledge $b a$ creates the opportunity for participants to work together in a creative place (e.g. in a community or an enterprise) for an enterprise which desires to promote knowledge creation on the website then by proceeding with the implementation of knowledge management systems to bolster corporate knowledge management and effectively promote the firm's competitiveness.

Regardless of the quite valuable empirical results are revealed by this research, several limitations of this study are still remained. First, due to the data was only gathered in Taiwan and the distribution of the scale and type of the enterprise we surveyed, there may exist some divergences compare with those in other countries. Therefore, the outcomes we obtained cannot be concluded. However, they are still worth applying to many Asian countries or areas such as Hong Kong, Korea, Singapore or other developing countries, whose dominant businesses are very much alike to the OEMs/ODMs in Taiwan. Second, we considered this case study only as one empirical illustration of many other possible implementation processes. The authors do not assume that this organization can represent or that its specific situation is appropriate to all other business enterprises. In the future, the scholars interested in these certain topics are therefore encouraged to triangulate its findings through analyzing the variables generated from this investigation.

\section{Ethics}

This article is original and contains unpublished material. The corresponding author confirms that there are no ethical issues involved.

\section{References}

Aghdasi, M. and N.G. Tehrani, 2011. Knowledge creation in an operational setting: A case study in an auto manufacturing firm. African J. Bus. Manage., 5: 7828-7835. 
Argyris, C. and D.A. Schon, 1996. Organizational Learning 11: Theory, Method and Practice. Addison-Wesley Publishing Company, Reading, ISBN-10: 0201629836, pp: 305.

Bartolacci, C., C. Cristalli, D. Isidori and F. Niccolini, 2016. $B a$ virtual and inter-organizational evolution: a case study from a EU research project. J. Knowl. Manage., 20: 793-811.

Bosom, Á., E. Fernández, M. J. Hernández, F.J. García and A. Seoane, 2007. The tutor online approach. J. Cases Inform. Technol., 9: 61-74.

Carlucci, D. and G. Schiuma, 2007. Knowledge assets value creation map: Assessing knowledge assets value drivers using AHP. Expert Syst. Applic., 32: 814-821.

Coulson-Thomas, C., 2004. The knowledge entrepreneurship challenge: Moving on from knowledge sharing to knowledge creation and exploitation. Learning Organization, 11: 84-96.

Emig, J., 1983. The Web of Meaning. 1st Edn., Upper Monclair, NJ, Boyton/Cook.

Feller, J., A. Farhankangas and R. Smeds, 2006. Process learning in alliances developing radical versus incremental innovations: Evidence from the telecommunications industry. Knowl. Process Manage., 13: 175-191.

Finger, S., D. Gelman, A. Fay, M. Szczerban and A. Smailagic et al., 2006. Supporting collaborative learning in engineering design. Expert Syst. Applic., 31: 734-741.

García-Muiña, F.E. and J.E. Navas-López, 2007. Explaining and measuring success in new business: The effect of technological capabilities on firm results. Technovation, 27: 30-46.

Grossman, M., 2004. The role of trust and collaboration in the internet-enabled supply Chain. J. A. Acad. Bus., 5: 391-396.

Hamel, J., S. Dufour and D. Fortin, 1993. Case Study Method. Thousand Oaks, CA: Sage Publication.

Hemetsberger, A. and C. Reinhardt, 2006. Learning and knowledge-building in open-source communities: A social-experiential approach. Manage. Learning, 37: 187-214.

Heng, M.S.H., 2001. Mapping intellectual capital in a small manufacturing enterprise. J. Intellectual Capital, 2: 53-60.

Johnson, D.E.L., 1998. Knowledge management is a new competitive edge. Healthcare Strategic Manage., 16: 2-3.

Kodama, M., 2005. Knowledge creation through networked strategic communities: Case studies on new product development in Japanese companies. Long Range Planning, 38: 27-41.

Kogut, B. and U. Zander, 1993. Knowledge of the firm and the evolutionary theory of the multinational corporation. J. Int. Bus. Stud., 24: 625-645.
Krahe, J.A., C. Lalley and N.M. Solomons, 2014. Beyond survival: Fostering growth and innovation in doctoral study--a concept analysis of the ba space. Int. J. Nursing Educ. Scholarship, 11: 11-18.

Kwon, O., 2006. The potential roles of context-aware computing technology in optimization-based intelligent decision-making. Expert Syst. Applic., 31: 629-642.

Lin, F. and C. Hsueh, 2006. Knowledge map creation and maintenance for virtual communities of practice. Inform. Processing Manage., 42: 551-568.

Malhotra, A., S. Gosain and O.A. El Sawy, 2005. Absorptive capacity configurations in supply Chains: Gearing for partner-enabled market knowledge creation. MIS Quarterly, 29: 145-187.

Mohamed, M., M. Stankosky and A. Murray, 2004. Applying knowledge management principles to enhance cross-functional team performance. J. Knowl. Manage., 8: 127-127.

Nonaka, I. and N. Konno, 1998. The concept of "ba": Building a foundation for knowledge creation. California Manage. Rev., 40: 40-54.

Nonaka, I. and H. Takeuchi, 1995. The Knowledge Creating Company: How Japanese Create the Dynamics of Innovation. 1st Edn., Oxford University Press, New York, NY.

Nonaka, I., R. Toyama and N. Konno, 2000. SECI, $B a$ and leadership: A unified model of dynamic knowledge creation. Long Range Planning, 33: 5-34.

Polanyi, M., 1966. Knowing and Being. 1st Edn., University of Chicago Press, Chicago.

Ramírez, A.M. and V.J.G. Morales, 2011. Improving competitiveness trough creation of knowledge and reverse logistics. Eng. Economi., 22: 443-450.

Roy, M., T. Chatterjee and L. Linnanen, 2012. Exploring effective knowledge management to improve organizational performance in globalized environment: An empirical study. Adv. Manage. Applied Economi., 2: 205-213.

Ryu, C., Y.J. Kim, A. Chaudhury and H.R. Rao, 2005. Knowledge acquisition via three learning processes in enterprise information portals: Learning-byinvestment, learning-by-doing and learning-fromothers. MIS Q., 29: 245-277.

Senker, J., 1995. Tacit knowledge and models of innovation. Industrial Corporate Change, 4: 425-447.

Shin, M., T. Holden and R.A. Schmidt, 2001. From knowledge theory to management practice: Towards an integrated approach. Inform. Processing Manage., 37: 335-355.

Soliman, F. and M. Youssef, 2001. The impact of some recent developments in e-business on the management of next generation manufacturing. Int. J. Operations Produc. Manage., 21: 538-566. 
Su, C., Y. Chen and D.Y. Sha, 2007. Managing product and customer knowledge in innovative new product development. Int. J. Technol. Manage., 39: 105-105.

Thang, N.N., T. Quang and N.H. Son, 2013. Knowledge creation and green entrepreneurship: A study of two Vietnamese green firms. Asian Acad. Manage. J., 18: 129-151.

Turban, E., E. Mclean and J.C. Wetherbe, 2001. Information Technology for Management. 1st Edn., John Wiley and Sons, Inc.
Ueki, H. and M. Ueki, 2009. Enabling knowledge creation and international deployment of best practices in large Japanese firms. J. Tokyo Keizai University, 266: 3-35.

Wolfe, M., 2007. Broadband videoconferencing as a knowledge management tool. J. Knowl. Manage., 11: 118-118.

Yin, R.K., 1994. Case Study Research - Design and Methods. 2nd Edn., London Sage Publicatio, Thousand Oaks. 